\title{
ENTRE A FRUIC̣ÃO DO PRESENTE E O INVESTIMENTO NO FUTURO: PRÁTICAS EXTRACURRICULARES ESTUDANTIS EM COLÉGIOS PRIVADOS
}

\author{
Maria Luísa Quaresma \\ Universidad Autónoma de Chile
}

RESUMO: Neste artigo refletiremos sobre as atividades extracurriculares dos jovens das classes dominantes, tendo por base a realidade educativa de dois prestigiados colégios privados sediados em Lisboa. Após a revisão da literatura sociológica sobre a educação não formal e a importância das atividades extracurriculares no quotidiano dos jovens e das famílias e a apresentação das principais técnicas de investigação (inquérito e entrevistas), analisaremos os resultados empíricos sobre a adesão às práticas extracurriculares dos alunos desses colégios e os sentidos que lhes atribuem as respetivas famílias. Concluímos que a frequência dessas atividades é massificada entre os jovens dessas escolas e que essas preferências estão longe de ter um cunho marcadamente classista, refletindo, para além disso, o ethos da respetiva escola frequentada. Em sintonia com a literatura sociológica, concluímos ainda que a instrumentalidade e a lógica de investimento no futuro subjazem às opções juvenis e também parentais para a ocupação do tempo livre.

Palavras-chave: Atividades extracurriculares. Socialização. Colégios privados. Classes dominantes.

"Doutorada em Sociologia pela Faculdade de Letras da Universidade do Porto. Pesquisadora e professora na Universidad Autónoma de Chile e no Grupo de Pesquisa: Instituto de Estudios Sociales y Humanísticos, Facultd de Ciencias Sociales y Humanidades. E-mail: marialuisa.rocha@uautonoma.cl 


\title{
BETWEEN PRESENT'S FRUITION AND INVESTMENTS IN THE FUTURE: STUDENTS' EXTRACURRICULAR PRACTICES IN PRIVATE SCHOOLS
}

\begin{abstract}
Based on a study about two prestigious private schools located in Lisbon, we analyze the extracurricular activities attended by upper class students. Firstly, the paper discusses the non-formal education and the importance of these activities in the daily life of these students. Then, we present methodological strategy (methods and techniques) and main empirical results, related to the students' involvement in extracurricular activities and perceptions shared by their parents about it. We conclude that the students participate massively at these non-formal initiatives and that their preferences are eclectic - and not linearly correlated with their social class. The initiatives they choose are deeply linked to the ethos of the school attended. We also conclude that the students and parents' choice of extracurricular activities are influenced by the instrumentality and by the desire of making an investment on their future.
\end{abstract}

Keywords: Extracurricular activities. Socialization. Private schools. Upper classes.

\section{INTRODUCุÃO}

As atividades extracurriculares vêm assumindo uma crescente importância no quotidiano dos jovens. Ainda que a adesão a essas práticas e a sua valorização assumam contornos distintos - em função, nomeadamente, da pertença de classe -, a ocupação do tempo livre é uma preocupação crescente das famílias, mas também das escolas e, inclusive, do Ministério da Educação Português.

Neste artigo, faremos uma reflexão sobre as atividades extracurriculares como complemento educativo, focalizando a nossa atenção nos alunos de dois dos mais reputados colégios privados de Lisboa (Portugal). Quais serão as atividades extracurriculares que mais motivam os jovens dessas escolas de prestígio? Terão elas um cunho de distintividade social? Serão as opções juvenis permeáveis à influência da socialização familiar e escolar? Que sentidos atribuirão pais e estudantes a essas práticas? Serão elas encaradas na sua vertente mais expressiva ou mais instrumental?

Para respondermos a essas interrogações de pesquisa, começaremos por fazer uma revisão da literatura existente sobre as atividades extracurriculares, sobre a sua importância para o desenvolvimento integral dos jovens e sobre o (diferencial) investimento das famílias nessas práticas. Seguidamente, faremos uma breve apresentação dos colégios estudados e traçaremos os principais contornos técnico-metodológicos da nossa pesquisa. Finalmente, analisaremos as 
atividades extracurriculares que colhem a preferência dos estudantes inquiridos e aquelas em que eles mais participam - desporto, música, aulas de línguas, dança, teatro, artes plásticas...-, procurando refletir sobre o grau de permeabilidade dessas escolhas às influências socializadoras da escola. Ao mesmo tempo, daremos voz aos pais, apurando as suas percepções sobre essas práticas de tempo livre: serão uma "fonte de prazer" ou um trunfo mobilizável para o futuro?

\section{AS ATIVIDADES EXTRACURRICULARES COMO COMPLEMENTO EDUCATIVO}

As atividades extracurriculares integram hoje o quotidiano da maioria dos alunos e das respectivas famílias, sendo reconhecidas como uma parte essencial da experiência escolar. No entanto, elas suscitaram, durante muito tempo, fortes reservas aos educadores, que as viam como atividades meramente recreativas. Na linha das conclusões de Coleman (1961), elas eram acusadas de retirar tempo disponível para o trabalho escolar e, nessa medida, de ser prejudiciais ao bom desempenho do ofício do aluno, o que justificava o seu desencorajamento (MARSH; KLEITMAN, 2002). A esse ceticismo não era alheia a concepção de que a educação se reduz à escola e o consequente não reconhecimento das potencialidades educativas de outros espaços e tempos que não os escolares (SUE, 2006). As críticas que se tecem sobre os sistemas formais de educação no final dos anos 60 - e que têm expressão pública no relatório de Coombs (1968), justamente intitulado The World Education Crisis - vêm dar força aos que alertam contra a

[...] identificação, errónea, entre universo educativo e universo escolar (que) apenas nos permite aceder a uma visão truncada, incompleta e redutora de um processo educativo definido a partir de organizações especializadas e balizadas por sessões formais, programas, avaliações e certificados (CANÁRIO, 2006, p. 196).

É nesse quadro de profundo desencanto que emerge o conceito de uma nova configuração educativa: a educação não formal. Definida por La Belle (1986, p. 2) como "toda a atividade educacional organizada, sistemática, executada fora do quadro do sistema formal para oferecer tipos selecionados de ensino a determinados subgrupos da população", a educação não formal é profeticamente anunciada por Coombs (1968) como o paradigma capaz de contribuir para o progresso dos indivíduos e dos países que, dos mais aos menos desenvolvidos, nela encontrarão um aliado para ultrapassar a inércia do sistema educativo formal ${ }^{1}$. 
Como também constatará Sue (2006), quatro décadas depois, a importância de multiplicar as ocasiões, os tempos e os espaços de apropriação dos saberes e de aquisição de competências é tanto maior quanto for a incapacidade escolar, ainda aprisionada pela lógica da mera "aquisição de informações ou conhecimentos" (TEDESCO, 2008, p. 116), de desenvolver nos alunos o leque de skills requeridos pelo mercado de trabalho no atual "quadro de uma economia de mudança e de inovação" (SUE, 2006, p. 197): personalidade, criatividade, originalidade, sentido prático, espírito de equipe, capacidade de liderança, competências e disposições, "menos desenvolvidas e exigidas pela escola mas recompensadas posteriormente no mercado de trabalho e na vida social" (VAN ZANTEN, 2009, p. 110). As atividades extracurriculares enquadram-se nesse novo paradigma de educação para além da sala de aula defendido por Paulo Freire e perspectivado numa lógica não de oposição, mas de complementaridade à educação formal, nenhuma dessas modalidades educacionais devendo ter "supremacia sobre a outra nem diminuir ou depreciar uma ou outra forma de educação" (LIBÂNEO, 2005, p. 89). Hoje, parece reunido um largo consenso da comunidade científica sobre a importância educativa das atividades extracurriculares que, nas palavras de Barrère (2010, p. 1), estarão longe da "esfera de futilidade generalizada", constituindo antes "um verdadeiro programa informal de educação". Elas afirmam-se como um espaço de socialização e de formação do carácter, permitindo, pela sua natureza eletiva, a autonomização progressiva dos adolescentes das pressões parentais e amicais e, nessa medida, proporcionando a expressão da "singularidade adolescente" num "universo marcado por múltiplos processos de estandardização" (BARRÈRE, 2010, p. 1).

A formação da identidade dos adolescentes é também potenciada peladescoberta das suas preferências, pelodesenvolvimento de skills e pela interação com os pares, propiciados por atividades extracurriculares (YOUNISS et al., 2002; ECCLES; BARBER, 1999), que estão ainda positivamente associadas ao desenvolvimento de skills sociais e emocionais (SHELLY, 2011), ao sentimento de bem-estar em diferentes domínios (BUSSERI et al., 2006), às mais baixas taxas de comportamentos antissociais, ao desenvolvimento de laços sociais (CHIA, 2005) e ao alargamento das redes sociais. Acresce que ao promover o fortalecimento da autoestima e da resiliência psicológica (SIMPKINS; ECCLES; BECNEL, 2008), o desenvolvimento da capacidade de iniciativa e da motivação, da tolerância ao stress e da proatividade (KRAIMER; SEIBERT; CRANT, 2001), as atividades extracurriculares estão a disponibilizar aos alunos ferramentas 
mobilizáveis não só no plano profissional, em termos de acesso e de sucesso no mercado laboral (CHIA, 2005), mas também no campo escolar, hoje marcado por uma forte competitividade. Zaffran (2011), a propósito das aulas de música e dança e até das atividades desportivas, mostra como a frequência dessas atividades ajuda os jovens a internalizar as disposições e os valores necessários para uma integração escolar bem-sucedida, reforçando o ethos escolar: eles aprendem a obedecer a regras, a aceitar os exercícios de repetição e de treino, a manter elevados níveis de concentração e de rigor, a submeter-se a uma disciplina corporal e a um controle das emoções. Também Nogueira et al. (2007) sublinharam o contributo para o sucesso acadêmico não só das aulas de música mas, também, das de informática, de artes ou de línguas, cuja forma escolar contribui para desenvolver nos jovens a capacidade de concentração e para promover neles hábitos de assiduidade e estratégias de gestão do tempo. Vários estudos apontam, de fato, no sentido de o envolvimento em atividades extracurriculares melhorar o desempenho acadêmico (ECCLES; BARBER, 1999; MARSH; KLEITMAN, 2002), fortalecer os laços com a comunidade escolar, criar disposições mais favoráveis à adesão ao projeto acadêmico e aumentar as aspirações em termos de percurso escolar (DARLING, 2005).

\section{ADESÃO PARENTAL ÀS ATIVIDADES EXTRACURRICULARES}

A possibilidade de estas atividades se traduzirem em vantagens transferíveis para o campo escolar será um fator que contribuirá para a receptividade dos pais a esse tipo de ocupação do tempo livre uma receptividade tanto mais generalizada quanto é hoje socialmente transversal a preocupação das famílias com a escolarização dos filhos e a mobilização, ainda que diferencial, das suas práticas educativas para que eles alcancem o sucesso escolar, tendencial e redutoramente entendido no seu sentido institucional de linearidade da carreira acadêmica (VIEIRA; PAPPÁMIKAIL; NUNES, 2012). Um estudo de Montandon (2010) centrado nas representações sociais dos pais sobre as atividades extracurriculares de educação musical dá conta, efetivamente, da existência de pais que admitem procurar nessas aulas métodos educativos e valores - competição, concorrência, rivalidade, rigor - que poderão ser úteis no campo escolar e que eles identificam nos conservatórios de música, onde os filhos encontram um prolongamento do mundo escolar. Há outros pais, no entanto, que procuram nas aulas de música um outro modelo de aprendizagem. 
Delegando na formação musical uma função complementar ou suplementar da educação escolar, optam pela inscrição dos filhos em associações e/ou centros de animação, onde eles aprendem música pelo prazer de aprender, sem a pressão dos exames e das classificações, sem o estresse dos deveres e num clima de cooperação e motivação.

A variável pertença de classe introduz cambiantes quer no grau de penetrabilidade das famílias à racionalidade escolar na organização do tempo livre dos filhos, quer nos recursos informacionais e econômicos para lhes proporcionar "lazeres inteligentes". Assim, enquanto nas famílias populares prevalece o modelo de "crescimento natural das crianças" (LAREAU, 2007, p. 13), caracterizado pela ocupação do tempo livre em brincadeiras espontâneas que não deixam de ser fundamentais para que elas possam crescer, descobrir-se e construir-se enquanto pessoas (GLASMAN, 2005), já nas famílias das classes médias há um forte investimento na "concerted cultivation" (LAREAU, 2007, p. 13) dos filhos, a quem são proporcionados lazeres culturais e atividades extracurriculares de natureza estruturada, vistas como mais-valias para uma socialização bem-sucedida.

Também Van Zanten (2009) destaca o pendor pedagogizante dos lazeres infanto-juvenis dessas classes ${ }^{2}$, lembrando como elas encaram as atividades desportivas e culturais não apenas como parte integrante do desenvolvimento cultural e social das crianças mas também como um aliado indispensável para que elas "[...] possam suportar fisicamente e mentalmente o trabalho exigido pela escola" (VAN ZANTEN, 2009, p.110) - preocupações que, no entanto, a autora diz serem muito mais vincadas nos pais tecnocratas do que nos pais intelectuais, cuja ação educativa é também norteada pela lógica da expressividade. Os estudos de Pinçon e PinçonCharlot (2007), Mension-Rigau (2007) e Vieira (2003) confirmam a centralidade atribuída aos lazeres inteligentes pelas classes do topo da hierarquia social, que eles integram nas elites. Mobilizadas pelo ideal de "formação integral", acreditando garantir aos seus herdeiros o habitus de classe distinto e distintivo que marcará a diferença em tempos de democratização escolar, essas famílias providenciam aos filhos as condições ideais para a frequência de atividades extracurriculares: seja inscrevendo-os em seletivos colégios dotados das infraestruturas e dos recursos humanos necessários para lhes disponibilizar, mediante pagamento extra, um alargado leque de iniciativas lúdico-educativas, seja matriculando-os em instituições privadas, como é o caso dos conservatórios ou das escolas de ballet, seja proporcionando-lhes aulas particulares em contexto doméstico. 
Durante muito tempo privilégio de grupos sociais restritos, as atividades extracurriculares passarão a estar acessíveis a todas as crianças com a implementação, em Portugal, da Escola a Tempo Inteiro - uma medida de promoção de igualdade de oportunidades que pecará por se deixar aprisionar pelo "escolocentrismo", comprovando a dificuldade de pensar a educação para além do escolar (PALHARES, 2009).

\section{METODOLOGIA}

Os dados de suporte a este artigo resultam de uma pesquisa de doutorado realizada entre 2008 e 2011 em dois reputados colégios privados de Lisboa (um laico e um religioso) e que teve por objetivo captar as representações sociais dos agentes educativos sobre o sucesso e sobre os fatores internos e externos à escola que o potenciam. Alcançamos essa meta de pesquisa recorrendo a um conjunto diversificado de técnicas de recolha de dados. $\mathrm{Na}$ fase exploratória, entrevistamos os diretores e os responsáveis de ciclo de cada um dos colégios, bem como os representantes das principais associações de pais, de alunos e de antigos alunos. $\mathrm{Na}$ fase principal, aplicamos um inquérito por questionário a uma amostra representativa (em termos de sexo, ano de escolaridade e agrupamento de estudos) de 475 alunos (166 do religioso e 309 do laico) do $9^{\circ}$ ao $12^{\circ}$ ano e recortada de um universo de 874 jovens (435 da escola confessional e 439 da escola laica). Para complementar essa informação extensiva, realizamos quatro grupos de discussão com alunos e professores e 19 entrevistas semidiretivas a pais e a ex-alunos. Os dados foram sujeitos a uma análise de conteúdo qualitativa, tendo sido adotado como unidade de análise o tema. Durante os três anos em que permanecemos nesse terreno, realizamos observações diretas quer do quotidiano escolar nos espaços e tempos não letivos, quer dos rituais e cerimônias dos dois colégios.

Os colégios em análise são dois reconhecidos estabelecimentos de ensino localizados em Lisboa e que foram desde sempre frequentados pelas classes dominantes portuguesas. A escola religiosa é tutelada pela Companhia de Jesus e foi inaugurada na década de 1940, cerca de 30 anos depois da implementação do regime republicano que, mobilizado pelos ideais de laicidade e de educação pública e democrática, encerrara o colégio até então dirigido pela companhia e onde estudavam grandes vultos da época, como Almada Negreiros. Com o propósito de construir uma escola que permitisse reatar com a sua missão educativa, a companhia adquire, em 1947, em 
pleno período ditatorial do Estado Novo, uma quinta e um solar que foram convertidos em estabelecimento de ensino. Para nome do novo colégio que então se inaugurava foi escolhido o de um missionário jesuíta português, mártir na Índia, que acabara de ser canonizado. O colégio laico, por sua vez, abriu as suas portas em pleno regime republicano, no ano de 1936, e teve como fundador uma figura que, além de notável pedagogo, se destacou na vida política do seu tempo pela adesão aos ideais republicanos e, mais tarde, pelo combate à ditadura salazarista. Concebido como um estabelecimento de ensino livre e pedagogicamente avançado acolheu no seu corpo docente personalidades de elevada craveira até então afastadas do ensino público por razões ideológicas, depressa se afirmando, desse modo, no atávico panorama educativo português como um reduto de liberdade de expressão e de afirmação dos valores da cultura por onde passaram, como alunos, algumas figuras relevantes da vida político-cultural.

A história e a tradição de cada um dos colégios marcam, inegavelmente, os respectivos projetos educativos. O colégio religioso tem por meta a formação integral do indivíduo, definindo-a, no seu Projeto Educativo, como a conjugação de três dimensões fundamentais: pessoal, traduzida na construção de uma personalidade vincada e coesa; social, materializada na educação para um ser "de relação" com a alteridade e para o "serviço dos outros"; e religiosa, patente no acompanhamento dos "[...] alunos no seu crescimento da Fé, centrada em Cristo [...]" (Projeto Educativo, colégio religioso pesquisado, s/p.). O colégio laico tem também por meta a formação integral dos alunos, educando-os segundo os "grandes valores humanistas" (Projeto Educativo, colégio laico pesquisado, s/p.) que presidiram à fundação desse estabelecimento de ensino, apostando no desenvolvimento do pilar humano (educação para a autonomia, a reflexividade, a criatividade), acadêmico (aquisição do patrimônio linguístico, literário e científico) e de cidadania (participação na vida cívica).

Essa formação de banda larga preconizada por ambos os colégios dá resposta, como dizem Pinçon e Pinçon-Charlot (2007), aos desígnios socializadores das classes dominantes, que constituem o público dessas escolas, como os dados do inquérito comprovam. Com efeito, elas são frequentadas por jovens provenientes de famílias com elevados capitais econômicos e culturais, cujos progenitores são, na sua maioria, profissionais nas áreas da engenharia, da medicina, da economia e gestão de empresas. Os lugares de classe de origem dos alunos, identificados por meio de uma combinatória entre as dimensões 
profissional (profissão e situação na profissão dos progenitores) e cultural (nível de habilitações), distribuem-se, na quase totalidade, pela burguesia (52,7\%), repartida entre a Burguesia Dirigente e Profissional (BDP), 31,9\%, a Burguesia Empresarial e Proprietária (BEP), 20,8\%, e pela Pequena Burguesia Intelectual e Científica (PBIC), 41,4\%. A forte capitalização cultural dos pais é visível no fato de $38,1 \%$ das mães ter completado a graduação, 23,8\% o mestrado, 12,1\% o doutorado e $9,8 \%$ o pós-doutorado, percentagens que entre os pais atingem, respetivamente, 33,2\%, 23,1\%,17,9\% e 10,6\%. A expressividade desses valores sobressai perante os $17 \%$ de portugueses entre os 25 e 64 anos que, em 2011, tinham completado a graduação (OCDE, 2013).

\section{ATIVIDADES EXTRACURRICULARES: GOSTOS JUVENIS E INFLUÊNCIA DA ESCOLA}

As atividades extracurriculares são parte integrante da vida dos alunos desses dois colégios privados, o que vem de encontro às conclusões de alguns estudos sobre a importância conferida pelas famílias das classes dominantes a esse tipo de ocupação do tempo livre (VAN ZANTEN, 2009; VIEIRA, 2003). Com efeito, 73\% dos jovens inquiridos disseram frequentar, pelo menos, uma atividade extracurricular, selecionada de um leque que abrange desde as mais democratizadas, caso do desporto ou das aulas de línguas, até as que têm um cunho socialmente mais seletivo, como é o caso da música, do teatro ou dos ateliês de artes plásticas e de fotografia.

Vendo essas atividades como uma possibilidade de o aluno "[...] fomentar interesses, ou de desenvolver interesses que ultrapassam o mero saber académico da sala de aula" (Diretor do $3^{\circ}$ ciclo do colégio religioso), esses colégios fazem questão de ir ao encontro das preferências de lazer dos seus jovens "clientes", numa lógica de atuação que os diferenciará as escolas públicas, onde os projetos de ocupação extracurricular do tempo livre são delineados sem o prévio "trabalho de diagnóstico das necessidades, expectativas, aspirações e vivências” (LOPES, 2010, p. 286) dos alunos. Entre as propostas extraescolares do colégio laico sobressaem-se as de âmbito musical, mas também a dança (hip-hop, dança jazz, ballet), o teatro, os meios audiovisuais e, ainda, as atividades desportivas como a ginástica, a esgrima, o judô e o tênis. A instituição religiosa, por sua vez, sobressai-se no campo das atividades desportivas, que são uma área com tradição nesse colégio, mas conta igualmente com cursos de dança, teatro, bateria, piano, xadrez, entre outros. As atividades são 
realizadas, em média, duas vezes por semana e no horário pós-letivo, ou seja, depois das $17 \mathrm{~h}$. Estando distribuídas pelos diferentes dias da semana para motivar os alunos a participar em mais de uma delas, as atividades têm uma duração entre uma e duas horas (à semelhança do que sucede na generalidade das atividades extraescolares dinamizadas pelas instituições não escolares).

Pais e filhos dizem-se satisfeitos com a oferta dos respetivos colégios, o que não impede a existência de um número expressivo de alunos com atividades extracurriculares no exterior da escola $(46,5 \%)^{4}$. As razões invocadas para essa externalização vão desde a convicção de que num conservatório de música, numa equipe desportiva ou num instituto de línguas os alunos terão um acompanhamento mais profissionalizado do que nos respectivos colégios, até ao desejo de um alargamento dos horizontes de sociabilidade, confinados nesses colégios a "um certo nicho de sociedade", como diz uma mãe (mãe, colégio laico, PBIC, 36 anos). Com efeito, ainda que a maioria das atividades fora do colégio envolva um custo mensal que exclui delas os setores mais vulneráveis da sociedade, elas não deixam de estar acessíveis a uma maior diversidade social do que a existente nesses dois seletivos colégios, o que contribuirá para essa percepção dos pais de um alargamento das redes de relações sociais. Para essa percepção contribuirá também, por exemplo, o fato de as atividades de futebol serem praticadas por muitos desses alunos nas instalações das suas equipes desportivas, que numa política de incremento ao desporto juvenil abrem as suas "escolinhas de futebol" a amplas camadas da população, mediante uma mensalidade que democratiza a sua frequência.

O desporto surge, de fato, no topo das preferências desses alunos. Com mais praticantes do sexo masculino do que feminino $(69,6 \% \text { contra } 46,4 \%)^{5}$, confirmando o peso da socialização de gênero, o desporto é praticado por $58 \%$ dos jovens desses dois colégios. A dimensão corporeísta da sociedade contemporânea ocidental e a "[...] atitude genérica de valorização e autorresponsabilização pelo design e performance do corpo [...]" (FERREIRA, 2004, p. 57), a que os jovens mais escolarizados e de estatuto social mais elevado são particularmente receptivos, ajudará a compreender a centralidade das atividades desportivas no lazer juvenil. Acresce que a prática desportiva integrou, desde sempre, o projeto formativo dos jovens "herdeiros", sendo vista pelas classes dominantes como parte integrante da "educação total" (VAN ZANTEN, 2009) e

[...] como forma de domesticação do corpo e das emoções, como pretexto socializador com iguais, como exercício de autonomia, como signo identificador do grupo, 
como autêntico ritual grupal e, também, como expressão simbólica da capacidade económica para poder "gastar" improdutivamente o tempo. (VIEIRA, 2003, p. 531).

Quanto às modalidades praticadas, a sua escolha não estará imune à diferenciação social que, na perspetiva bourdieusiana, está na base das variações dos gostos e dos desgostos por diferentes práticas culturais e estilos de vida. Como também será reafirmado pela sociologia do desporto, o lugar que o indivíduo ocupa no espaço social condiciona não apenas o tipo de relação que ele estabelece com o seu corpo, mas também os usos que lhe dá, nomeadamente em termos desportivos (POCCIELLO, 1981). Assim, de acordo com Kellerhals e Montandon (1991), as modalidades que colhem a preferência das classes do topo da hierarquia social e cultural são aquelas que se enquadram nos desportos de adaptação, promotores da destreza e da adaptabilidade (caso do surfe), e nos desportos de antagonismo, estimuladores do individualismo e do espírito competitivo, face a face (caso do tênis ou da esgrima). Pese embora as especificidades nacionais de cada contexto, encontramos entre esses estudantes portugueses similitudes com os jovens suíços. Esses tipos de modalidades têm, de fato, praticantes entre os alunos desses colégios, dos quais 10,6\% jogam tênis e 6,3\% fazem surfe/bodyboard/windsurf. O mesmo acontece com o tênis, um desporto integrado nas preferências burguesas, que, segundo um estudo sobre a classe dominante portuguesa realizado por Vieira (2003), ocupa o terceiro lugar no ranking das modalidades praticadas por esses alunos. No entanto, os desportos mais praticados são, precisamente, dois dos que Kellerhals e Montandon (1991) dizem ter idêntica proporção de praticantes entre as crianças de todos os meios sociais e que Loureiro (2011) identifica como as duas atividades desportivas mais praticadas pelos adolescentes portugueses: o futebol, desporto-rei sociedade portuguesa que aparece a liderar as preferências desses alunos, com 23,1\% de praticantes; e, com 17,7\%, a natação, "um desporto de endurance" com um forte componente de esforço físico, como os pesquisadores suíços constataram. No plano das práticas desportivas, parece visível a coexistência de "gostos democráticos", marcadamente influenciados pela cultura de massa, com "gostos distintos e distintivos" de classe, apontando no sentido da perda de unicidade disposicional do homem contemporâneo, que Lahire (2003) define como "plural".

Indo de encontro às preferências dos alunos pelo desporto, os dois colégios portugueses disponibilizam-lhes um amplo leque de atividades físicas que vão das mais massificadas às mais 
elitizadas, abarcando modalidades como o futebol, a natação, o handebol, o voleibol, a ginástica (acrobática e desportiva), o ballet, o judô, ou a esgrima. É na instituição religiosa que encontramos uma percentagem mais significativa de alunos a praticar atividades desportivas disponibilizadas pela escola, o que refletirá, a nosso ver, a maior centralidade conferida à dimensão desportiva por esse estabelecimento de ensino. Como lembra um dos alunos, "[...] o colégio - e isso também faz parte da nossa formação - tenta meter o desporto nas nossas vidas e acho que... e é conhecido por isso, conheço pessoas de fora que sentem isso, que o colégio focase muito no desporto [...]" (aluno, colégio religioso, PBIC, 16 anos). Tendo por meta a formação integral do indivíduo, princípio basilar da pedagogia inaciana, e implicando a educação da pessoa no total desenvolvimento físico, esse colégio não poderia deixar de conferir, no seu projeto educativo, uma atenção particular aos programas desportivos. Para além do fortalecimento do corpo, eles "[...] ajudam os jovens de ambos os sexos a aceitarem de bom grado os seus êxitos e fracassos, torna-os conscientes da necessidade de cooperar com os outros, usando as melhores qualidades pessoais para contribuírem para o maior bem de todo o grupo" (GRACOS, 2000, p. 15). A aposta na criação de infraestruturas para o exercício desportivo é notória por parte da direção desse colégio, que se beneficia da instalação numa espaçosa quinta com as necessárias condições logísticas para albergar equipamentos tão variados como piscina, quadras de tênis, rinque de patinagem, campo de hóquei em patins e futsal, além dos mais convencionais campos de futebol, de vólei e de basquetebol.

$\mathrm{Na}$ realização de eventos desportivos, animados pela participação de equipes estrangeiras dos colégios da mesma congregação religiosa, a direção encontra não só um instrumento ao serviço da criação e do reforço do esprit de corps e do sentido de emulação favorável à adesão dos alunos ao projeto escolar que lhes é proposto, mas também uma estratégia para trazer os pais à escola e fomentar o seu envolvimento na vida do colégio e dos seus filhos. A presença maciça e entusiástica das famílias, por nós testemunhada durante o trabalho de campo, foi particularmente visível nos torneios de futebol que galvanizavam tanto os adultos como os jovens.

Com um lugar importante na economia dos lazeres juvenis, a música também marca presença no quadro das atividades extracurriculares da juventude, estando entre as prioridades formativas das classes mais capitalizadas do ponto de vista socioeconômico e 
cultural (VIEIRA, 2003; KELLERHALS; MONTANDON, 1991). Tal como a prática desportiva, as atividades de âmbito musical cumprem uma função que extravasa a dimensão meramente lúdica, assegurando o desenvolvimento de requisitos que constituirão um capital social e simbólico de inegável valor para os jovens "herdeiros", como é o caso da sensibilidade artística e da cultura geral. $\mathrm{O}$ inquérito levado a cabo nesses colégios dá conta da existência de cerca de $20 \%$ de jovens que aprendem um instrumento ou frequentam aulas de canto e voz. A prática musical tem, no entanto, menos adeptos entre os alunos do colégio religioso - onde há aulas de piano, viola, guitarra elétrica e bateria - do que entre os do colégio laico, por razões que poderão prender-se com o fato de este último conferir maior centralidade a essa área extradisciplinar no seu Projeto Educativo do que o estabelecimento de ensino confessional. Marca distintiva do colégio laico e indisfarçável motivo de orgulho de toda a comunidade educativa é, por exemplo, a existência de uma orquestra de câmara que é presença incontornável e efusivamente aclamada em todas as cerimônias festivas desse estabelecimento de ensino. Com um reportório que soube abrir-se aos interesses musicais dos alunos, onde se incluem desde os hits comerciais e os ritmos de vanguarda pop à música clássica de compositores nacionais e internacionais, essa orquestra juvenil já projetou a sua imagem para além dos muros da escola, sendo as suas atuações no exterior da comunidade educativa vivenciadas como a prova da dedicação e da qualidade técnica alcançada pelo conjunto dos jovens violoncelistas, violonistas e executantes de viola portuguesa que dela fazem parte. Além da possibilidade de integrar essa orquestra, os alunos têm ao seu dispor aulas com instrumentos de elevada cotação simbólica, como é o caso do contrabaixo, do piano, da guitarra e da flauta transversal, podendo ainda ocupar o seu tempo livre em atividades de educação de voz (canto e dicção).

Uma outra atividade extracurricular com expressividade são as aulas de línguas, frequentadas por 21,1\% dos inquiridos. A aprendizagem de línguas, que as classes dominantes sempre tiveram como prioritária na educação dos seus "herdeiros" (VIEIRA, 2003; PINÇON; PINÇON-CHARLOT, 2007; MENSION-RIGAU, 2007), ganhou uma redobrada importância para esses grupos sociais no atual quadro de globalização econômica. A internacionalização do mercado laboral e a emergência de "global cities" onde se localizam as grandes sedes do poder financeiro, econômico e político tornaram incontornável, para os jovens "herdeiros", a experiência da mobilidade 
além-fronteiras, que hoje se inscreve nas estratégias individuais e familiares de reprodução social das elites (GUILLAUME; POCHIC, 2010). Conscientes de que estão socialmente predestinados a carreiras profissionais altamente competitivas e tendo também no seu horizonte de expectativas a internalização da sua carreira acadêmica, os alunos desses colégios mostram-se empenhados em fazer percursos escolares de excelência, vendo no aprofundamento dos conhecimentos de línguas um trunfo para facilitar o ingresso nas mais reputadas universidades estrangeiras. No contexto de (relativa) democratização do acesso ao Ensino Superior português, esses estabelecimentos de ensino internacionais configuram um novo signo de distinção a que uma percentagem significativa $(15,3 \%)$ desses jovens quer aceder. A opção por institutos de línguas com certificação internacional insere-se numa estratégia de antecipação do ingresso nas melhores escolas estrangeiras a que esses alunos e também os seus pais se mostram particularmente sensíveis, como se percebe quando um dos jovens nos diz, a propósito da escolha de um conhecido instituto: "[...] foi uma decisão da minha mãe, em primeiro lugar, com o objetivo de ter uma certificação de inglês ao nível dos exames da Universidade de Cambridge [...]" (aluno, colégio religioso, BDP, 17 anos).

Quanto às atividades de expressão artística, elas mobilizam uma percentagem de alunos que, embora menor do que a verificada noutros campos dos lazeres extracurriculares, nos parece expressiva, nomeadamente quando é tido em linha de conta o seu débil peso na ocupação de tempo livre da juventude portuguesa (GOMES, 2003). Assim, dos alunos inquiridos $7,2 \%$ praticam dança, $5,7 \%$ fazem teatro, $5,7 \%$ têm como lazer a fotografia e 5,1\% dedicam-se às artes plásticas - atividades que nos parecem configurar um signo distintivo de classe.

\section{A CENTRALIDADE DAS ATIVIDADES EXTRACURRICULARES PARA AS FAMÍLIAS}

Como pudemos testemunhar ao longo das entrevistas, os pais são unânimes no reconhecimento da importância das atividades extracurriculares, havendo mesmo quem defenda que a vida não se circunscreve à escola e fale da necessidade de as crianças "crescerem com outros objetivos de vida que não seja só o estudo" (mãe, colégio religioso, BEP, 42 anos). Na linha de Libâneo (2005), um outro pai mostra incompreensão pelo fato de as atividades extracurriculares não serem consideradas em plano de igualdade com as curriculares, em termos educativos, chegando mesmo a dizer: 
“O [termo] 'extracurricular' é uma coisa que já me causa incômodo. Porque a vida não é feita de uma vida e de uma extravida, a vida é tudo" (pai, colégio laico, BDP, 48 anos).

A maior parte dos pais percepciona os lazeres extracurriculares como momentos em que os filhos podem dar livre expressão aos seus gostos e em que podem descobrir "talentos ocultos" e disposições que a escola não valoriza (SINGLY, 1996). Como nos diz um dos pais, tendo as crianças "outros potenciais que têm de ser explorados - ou a música, ou a pintura, ou a leitura, ou jogar a bola, [...] ou lá o que for - devem fazê-lo" (pai, colégio laico, BDP, 48 anos). Eventualmente, as atividades extracurriculares poderão até levá-los a encontrar "caminhos diferentes, na vida" (mãe, colégio religioso, BEP, 42 anos). Confirmando as transformações da família moderna no sentido do primado do afetivo, da valorização das crianças, da assunção da responsabilidade dos pais pelo bem-estar físico e psicológico dos filhos e pela criação de condições para o desabrochar do seu "eu" (SINGLY, 1996), os entrevistados mostramse preocupados com "a felicidade [dos filhos] e a sua capacidade de realização" (pai, colégio religioso, BDP, 45 anos), que acreditam poder ser propiciadas também pelas atividades extracurriculares. Descrevem, com indisfarçável alegria, o entusiasmo com que veem os filhos envolverem-se nessas atividades: "Ele gosta disso, do 'E agora vêm os meninos da música!' Ele gosta, tem prazer! Já no judô é a mesma coisa, ele gosta disso" (mãe, colégio laico, PBIC, 32 anos).

Os princípios do respeito pela individualidade da criança e pela negociação familiar (SINGLY, 1996) também são seguidos no campo das atividades extracurriculares. Os pais dizem-se abertos para ouvir as preferências dos filhos e para as satisfazer, deixando-os escolher as atividades extracurriculares que mais lhes interessam, permitindolhes mudar quando dão sinal de insatisfação e negociando com eles a frequência de atividades dentro ou fora do colégio. Esta é uma questão que ganha premência na adolescência, altura em que os filhos tendem a reivindicar a sua autonomização familiar em termos de mobilidade (SINGLY, 2002) e em que as atividades extracurriculares se afirmam como o "espaço de expressão de singularidade adolescente" de que fala Barrère (2010). Seguindo essa linha de pensamento um dos pais dos alunos afirmou que "[...] pronto, lá está: vamos estando atentos, vamos vendo aquilo de que eles gostam mais e gostam menos. A [...] pediunos para sair da viola, porque não estava a gostar. E nós respeitámola e tirámo-la" (pai, colégio religioso, PBIC, 39 anos). Parece haver, 
no entanto, uma atividade não escolar em que os pais concedem menor autonomia decisória aos filhos: as aulas de línguas, muito em particular as de inglês. Nesse campo, os pais exercem alguma "diretividade", como se depreende pelas entrevistas. Tendo hoje o conhecimento de línguas, como já vimos, uma importância estratégica vital para o delinear de uma trajetória profissional e social de sucesso, os pais não podem limitar-se, na expressão de um dos entrevistados, a um mero "Olha, queres...?" que possa confrontá-los com um eventual "Não quero" (pai, colégio religioso, PBIC, 43 anos) da parte de um filho. Daí a necessidade de uma postura mais "diretiva", quer acionando estratégias de persuasão sob a forma de "[...] conversa preparatória para ele perceber que é importante e por que é que é importante [...]" (pai, colégio religioso, PBIC, 43 anos) o aprofundamento das aprendizagens escolares das línguas, quer "orientando" as escolhas no sentido de escolas de línguas com créditos firmados e com reconhecimento internacional, como as entrevistas documentam.

Mas a representação das atividades extracurriculares como fonte de prazer e de realização pessoal não impede os pais de, instrumentalmente, anteverem retornos, a curto e longo prazo, desses investimentos - desde logo -, porque enquanto pais "esclarecidos" saberão que crianças felizes e realizadas têm mais probabilidade de obter êxito escolar, mas também porque não ignorarão que é importante para elas "descontraírem um bocadinho da parte acadêmica" (mãe, colégio religioso, BEP, 42 anos), até porque a "descompressão" proporcionada por essas atividades poderá trazerlhes o necessário "equilíbrio" para superar o estresse das exigências escolares (VAN ZANTEN, 2009). As entrevistas não deixam dúvidas quanto às expectativas de que atividades extracurriculares contribuam para a internalização de disposições mobilizáveis não só na vida escolar (NOGUEIRA et al., 2007; ZAFFRAN, 2011) mas também na vida profissional (CHIA, 2005). Os pais dizem-nos que os lazeres extracurriculares ajudam os filhos a desenvolver a capacidade de concentração, a estabelecer metas e a lutar por elas, a respeitar regras e a assumir compromissos. Entre os benefícios de uma "agenda diária" bem preenchida de atividades, elencam o desenvolvimento da capacidade de organização, de responsabilização pelo cumprimento de horários, de priorização de tarefas e de gestão do tempo, destrezas que oferecem vantagens competitivas no mercado escolar e profissional e que vão sendo inculcadas desde cedo. Um dos pais exemplifica, com o caso do seu filho, a internalização precoce dessa "aptidão para um uso intensivo do tempo" (BOURDIEU, 1989, p. 117) e desse "sentido 
prático e organizacional" (SUE, 2006, p. 197) que são requeridos aos profissionais no quadro de uma economia de mudança e de inovação: "Se for preciso ir a estudar no metro, vai a estudar no metro, ou vai a fazer os trabalhos de casa no autocarro. É uma questão de organização e gestão de tempo" (pai, colégio religioso, PBIC, 39 anos).

Uma outra mais-valia dessas modalidades não formais de educação reside, segundo esses pais, na diversificação de experiências e, sobretudo, no alargamento das competências de sociabilidade, que eles acreditam ser mobilizáveis nos múltiplos contextos de vida com que os filhos irão confrontar-se e, nomeadamente, no campo profissional, onde as capacidades relacionais são qualidades tidas em linha de conta (SUE, 2006) até no processo do recrutamento, como nos diz um pai: "Aliás, é frequente, agora, quando se é posto perante uma oferta de emprego para determinado tipo de empresas fazer algumas perguntas viradas para isso, para ver como nós víamos a relação, enfim, [...] a relação com os outros" (pai, colégio religioso, BDP, 47 anos). É em nome de uma melhor preparação para enfrentar esses múltiplos contextos da vida que alguns pais dizem ter optado por inscrever os filhos em atividades extracurriculares fora do colégio, embora pese o incômodo, reconhecido por vários entrevistados, de ter de assumir o papel de "pais-táxi" (SINGLY, 2002, p. 33) enquanto as crianças não ganham autonomia para se deslocarem sozinhas.

Importa, também, em nome dessa preparação para o sucesso pessoal, social e profissional, conciliar a "inevitável adaptação ao presente com uma relativa fidelidade ao passado" (MENSIONRIGAU, 2007, p. 572). Assim, embora tendo procurado nesses estabelecimentos de ensino o "entre-soi" (VAN ZANTEN, 2009, p. 62) protetor de "contaminações" no processo de socialização dos filhos, os pais não deixam de admitir a necessidade/utilidade de as crianças terem algum contato com a "realidade do país, que não tem nada a ver com a realidade deste colégio" (mãe, colégio religioso, BEP, 42 anos). Ele ser-lhes-á proveitoso até como preparação para, mais tarde, "se inserirem em contextos de trabalho onde terão de interagir com diversas categorias profissionais e sociais" (VAN ZANTEN, 2009 , p. 191) e onde terão de dar provas da capacidade de abertura aos outros e da empatia, imprescindíveis para assumir funções de liderança. Frequentar atividades fora dos colégios, explica a mãe de um dos alunos, oferece a possibilidade de "uma experiência diferente, para ele ir conhecendo outro tipo de pessoas que ele vai ter de enfrentar quando sair do colégio" (mãe, colégio religioso, PBE, 50 anos) - 
uma experiência, acrescentamos nós, que permite uma tranquilizante "mistura controlada" (VAN ZANTEN, 2009, p. 67), até porque o público escolar com acesso a algumas dessas atividades extracurriculares pagas "não é muito para lá dum certo meio social" (mãe, colégio laico, PBIC, 46 anos), como acaba por reconhecer uma outra mãe...

\section{CONCLUSÃO}

Neste artigo, procuramos compreender como a ocupação do tempo livre é vivenciada pelos alunos - e respectivas famílias de dois prestigiados colégios privados. A grande maioria dos jovens inquiridos frequenta, pelo menos, uma atividade extracurricular, o que vem comprovar a importância conferida pelas famílias das classes dominantes às práticas de estimulação extracurriculares.

A atividade desportiva é aquela que mais colhe a preferência dos inquiridos, que têm como primeira e segunda opções modalidades socialmente transversais - caso do futebol e até da natação - e como terceira e quarta preferências desportos menos democratizados como o tênis e o surfe/windsurf/bodyboard. Em seguida, nas preferências desses jovens, aparecem as aulas de música e de línguas. Confirmando a influência da socialização escolar nas opções dos alunos, concluise que é no colégio religioso - escola que integra o desporto como pilar-chave do seu projeto educativo - que se encontra a maior percentagem de alunos dedicados à prática desportiva, enquanto na escola laica - tradicionalmente voltada para as artes e para a literatura - os alunos optam, em maior número, pelas aulas de música. A frequência de aulas de línguas é transversal às duas realidades educativas e será o reflexo de um investimento numa possível internacionalização da carreira (acadêmica e profissional). Mobilizados pelo ideal de formação holística, os pais veem nos lazeres extracurriculares uma excelente ferramenta para que os filhos, num exercício de progressiva afirmação de singularidade, possam descobrir "caminhos" e "talentos" secundarizados pela instituição escolar, mas que integram, para esses grupos sociais, o perfil do homem total. Momentos de "descompressão" considerados indispensáveis para superar o inevitável estresse imposto pela competitividade escolar, as atividades extracurriculares são ainda encaradas pelos pais como uma mais-valia em termos da aquisição de competências mobilizáveis no campo escolar e, em longo prazo, no campo profissional, como é o caso da capacidade de organização, da gestão do tempo ou 
do cumprimento de regras e de compromissos. A aprendizagem precoce de línguas obedece também a propósitos instrumentais, sendo fortemente incentivada pelos pais que, nesta matéria, admitem exercer alguma diretividade sobre as opções dos filhos, convictos de que o domínio de outros idiomas conferirá vantagens competitivas no acesso a uma prestigiada universidade internacional ou a uma carreira profissional além-fronteiras.

Quando frequentadas fora dos respectivos colégios, as atividades extracurriculares são ainda perspectivadas pelos pais como uma oportunidade para, num quadro de "abertura controlada" à alteridade, os filhos conviverem com a diversidade social e, desse modo, irem desenvolvendo as competências de sociabilidade interclassista de que, futuramente, terão de dar provas.

É entre o prazer e o dever, a fruição do presente e o investimento no futuro que parecem situar-se as motivações desses alunos e das respetivas famílias para a valorização e aposta nas atividades extracurriculares.

\section{REFERÊNCIAS}

BARRÉRE, A. Cultures juvéniles : diversité des références ou conformisme?, 2010. In: OCTOBRE, Sylvie; SIROTA, Régine (Dir.). Actes du colloque Enfance et cultures: regards des sciences humaines et sociales. Disponível em: <http://www.enfanceetcultures.culture.gouv. fr/actes/barrere.pdf $>$. Acesso em: 3 mar. 2013.

BOURDIEU, P. La noblesse d'Etat. Grandes écoles et esprit de corps. Paris: Les Editions de Minuit, 1989.

BUSSERI, M. A.; ROSE-KRASNOR, L.; Willoughby, T.; CHALMERS, H. A longitudinal examination of breadth and intensity of youth activity involvement and successful development. Developmental Psychology. Michigan, n. 42, p. 1313-1326, nov. 2006.

CANÁRIO, R. Aprender sem ser ensinado. A importância estratégica da educação não formal. In: LIMA, L.; PACHECO, J.; ESTEVES, M.; CANÁRIO, R. (Eds.) A Educação em Portugal (1986-2006): Alguns contributos de investigação. Lisboa: Sociedade Portuguesa de Ciências da Educação, 2006, p. 195-247.

CHIA, Y. Job offers of multi-national accounting firms: the effects of emotional intelligence, extracurricular activities and academic performance. Accounting Education. Amsterdam, v. 14, n. 1), p. 75-93, mar. 2005.

COLEMAN, J. The adolescent society: the social life of the teenager and its impact on education. Illinois: Free Press, 1961.

COOMBS, P. The World. Educational Crisis: A System Analysis. Londres: Oxford University Press, 1968.

CORIDIAN, C. Os usuários de produtos paraescolares: pais ou filhos? Educação \& Sociedade. Campinas, v. 24, n. 84, p. 945-953, set. 2003. 
DARLING, N. Participation in school-based extracurricular activities and adolescent adjustment. Journal of Leisure Research. Urbana, n. 37, p. 51-77, out., 2005.

ECCLES, J. S.; BARBER, B. L. Student council, volunteering, basketball, or marching band: What kind of extracurricular involvement matters? Journal of Adolescent Research. Thousand Oaks, v. 14, n. 1 p. 10-43, jan. 1999.

FERREIRA, V. Da reflexividade corporal entre os jovens portugueses: Uma realidade socialmente fragmentada. Actas do V Congresso Português de Sociologia. Braga: Universidade do Minho, p. 55-61, maio 2004.

GAUSSEL, M. Aux frontières de l'école ou la pluralité des temps éducatifs. Dossier d'actualité veille et analyses. Lyon, n. 81, p. 1-19, jan. 2013.

GLASMAN, D. Leur reste-t-il du temps pour jouer? Diversité: Ville école Intégration. Paris, n. 141, p. 51-57, jun. 2005.

GOMES, R. Sociografia dos lazeres e práticas culturais dos jovens portugueses. In: MACHADO, J.; VILLAVERDE, M. (Ed.) Condutas de Risco, Práticas Culturais e Atitudes Perante o Corpo. Oeiras: Celta Editora, 2003, p. 167-263.

GRACOS. Características da educação da Companbia de Jesus. Braga: Gracos, 2000.

GUILLAUME, C.; POCHIC, S. Mobilité internationale et carrières des cadres: figure imposée ou pari risqué? Formation emploi. Paris, n. 112, p. 39-52, out.-dez. 2010.

KELLERHALS, J. ; MONTANDON, C. Les stratégies éducatives des familles. Lausanne: Delachaux et Niestle, 1991.

KRAIMER, M.; SEIBERT, J.; CRANT, J. What do proactive people do? A longitudinal model linking proactive personality and career success? Personnel Psychology. Nova York, v. 54, n. 2, p. 845-874, dez. 2001.

LA BELLE, T. Nonformal Education in Latin America and the Caribbean: Stability, Reform, or Revolution? New York: Praeger, 1986.

LAHIRE, B. O homem plural. Lisboa: Instituto Piaget, 2003.

LAREAU, A. A desigualdade invisível: o papel da classe social na criação dos filhos em famílias negras e brancas. Educação em Revista. Belo Horizonte, n. 46, p. 13-82, dez. 2007.

LIBÂNEO, J. Pedagogia e Pedagogos para quê. São Paulo: Cortez, 2005.

LOPES, J. Do politeísmo cultural contemporâneo ao trabalho escolar de eliminação da dissonância. Sociologia. Porto, v. 20, p. 281-290, jul. 2010.

LOUREIRO, N. A Prática desportiva e a actividade fisica dos adolescentes portugueses: género, ambiente e lazer. 2011. 261 f. Tese (Doutorado em Ciências da Educação) - Programa de PósGraduação em Especialidade Educação para a Saúde, Universidade Técnica, Lisboa, 2001.

MARSH, H.; KLEITMAN, S. Extracurricular school activities: The good, the bad, and the nonlinear. Harvard Educational Review. Cambridge, v. 72, n. 4, p. 464-514, winter, 2002.

MENSION-RIGAU, E. Aristocrates et grands bourgeois. Perrin: Éditions Plon, 2007.

MONTANDON, F. Les représentations sociales des parents sur une activité extrascolaire: l'éducation musicale eu égard aux apprentissages scolaires. Actes du congrès de l'Actualité de la recherche en éducation et en formation (AREF). Genève (Université de Genève), p. 1-11, set. 2010.

NOGUEIRA, M. A.; NOGUEIRA, C.; FRANCO, C.; CUNHA, M. A.; VIANA, M. J.; RESENDE, T. A influencia da família no desempenho da Geração Escolar 2005. Belo Horizonte: UFMG, 2007. (Projeto de Pesquisa). 
OCDE. Education at a Glance: OECD Indicators. OECD Publishing, 2013. Disponivel em: < http://www.oecd.org/edu/Education-at-a-Glance-2014.pdf>. Acesso em: 29 jul. 2013.

PALHARES, J. Reflexões sobre o não escolar na escola e para além dela. Revista Portuguesa de educação. Braga, v. 22, n. 2, p. 53-84, fev. 2009.

PINÇON, M. ; PINÇON-CHARLOT, M. Sociologie de la bourgeoisie. Paris: La Découverte, 2007.

POCIELLO, C. La force, l'énergie, la grâce, les réflexes. Le jeu complexe des dispositions culturelles et sportives. In: POCIELLO, C. (Ed.). Sports et société Approche socioculturelle des pratiques. Paris: Vigot, 1981, p. 171-238.

SHELLY, B. Bonding, bridging, and boundary breaking: the civic lessons of high school student activities. Journal of Political Science Education. Orlando, v. 7, n. 3, p. 295-311, ago. 2011. SIMPKINS, S.; ECCLES, J.; BECNEL, J. The mediational role of adolescents' friends in relations between activity breadth and adjustment. Developmental Psychology. Michigan, v. 44, n. 4, p. 1081-1094, jul. 2008.

SINGLY, F. Le soi, le couple et la famille. Paris: Nathan, 1996.

SINGLY, F. La "liberté de circulation": un droit aussi de la jeunesse. Recherches et prévisions. Paris, n. 67, p. 21-36, 2002.

SUE, R. Les temps nouveaux de l'éducation. Revue du Mauss. Paris, n. 28, p. 193-203, 2006.

TEDESCO, J. O novo pacto educativo. Educação, competitividade e cidadania na sociedade moderna. 3. ed. Gaia: Fundação Manuel Leão, 2008.

VAN ZANTEN, A. Choisir son école: stratégies familiales et médiations locales. Paris: PUF, 2009. VIEIRA, M.; PAPPÁMIKAIL, L.; NUNES, C. Escolhas escolares e modalidades de sucesso no ensino secundário: percursos e temporalidades. Sociologia problemas e práticas. Lisboa, n. 70, p. 45-70, set.-dez. 2012.

VIEIRA, M. Educar herdeiros: práticas educativas da classe dominante lisboeta nas últimas décadas. Lisboa: Fundação Calouste Gulbenkian, 2003.

VINCENT, G.; LAHIRE, B.; THIN, D. Sobre a história e a teoria da forma escolar. Educação em Revista. Belo Horizonte, n. 33, p. 7-47, jun. 2001.

YOUNISS, J.; BALES, S.; CHRISTMAS-BEST, V.; DIVERSI, M.; MCLAUGHLIN, M.; SILBEREISEN, R. Youth civic engagement in the twenty-first century. Journal of Research on Adolescence. Malden, v. 12, n. 1, p. 121-148, fev. 2002.

ZAFFRAN, J. Le «problème» de l'adolescence: le loisir contre le temps libre, 2011. Sociologies. Disponivel em: <http://sociologies.revues.org/3446>. Acesso em: 25 jun. 2013.

\section{NOTAS}

${ }^{1}$ Saliente-se, a propósito das fronteiras entre os modos educacionais formais e não formais, que as atividades de educação não formal se deixaram "contaminar" pela forma escolar e se apropriaram das suas características (VINCENT; LAHIRE; THIN, 2001), perdendo o seu cunho de "não escolares". Refira-se ainda, a propósito dos conceitos "paraescolar" e "extraescolar", que embora não seja raro o seu uso como sinônimos, o termo "paraescolar" aplica-se ao conjunto de produtos que se destinam a ajudar os alunos na sua aprendizagem escolar, como é o caso dos livros de apoio escolar (CORIDIAN, 2003), enquanto o termo "extraescolar" se aplica às atividades que não remetem para a instrução propriamente dita do aluno, mas sim para a sua educação (GAUSSEL, 2013). 
${ }^{2}$ Classes superiores, integrando os tecnocratas e intelectuais.

${ }^{3} \mathrm{O} 9^{\circ}$ ano equivale ao último ano do Ensino Fundamental; o $12^{\circ}$ ano diz respeito ao último ano do Ensino Médio.

${ }^{4} \mathrm{~A}$ este elevado número não será alheio o fato de os alunos inquiridos terem entre 14 e 17 anos e disporem, portanto, de autonomia em termos de mobilidade.

${ }^{5}$ Diferença estatisticamente significativa (Pearson Chi-Square $=27,328$; $d f=3$; sig. 0,000).

Recebido: $21 / 01 / 2014$

Aprovado: 03/05/2015

Contato:

Maria Luísa Quaresma Avenida Pedro de Valdivia, 426, Providencia, Santiago |RM | Chile. 